\title{
A Comparative Study on Voice Distribution in English Abstracts between Chinese and English Power Papers
}

\author{
Jiao Liu, Rongying Zheng \\ School of Foreign Languages and Literature, North China Electric Power University, Beijing, China \\ somethingnew1989@163.com
}

\begin{abstract}
As many international scholars and editors currently advocated to use more active voice and less passive voice, this new trend aroused many Chinese reaearchers to conduct a comparative study on voice distribution in English abstracts between Chinese and foreign countries. To explore the voice distribution in English abstracts in Chinese and foreign power papers, we randomly sampled 200 English abstracts respectively from international and domestic power papers and analyzed the voice distribution in the abstracts. The results show that Chinese writers and translators tend to use more passive voice than foreign writers, especially in English-speaking countries, while the latter more frequently use active voice in their writings. To futher this study, the following gives a detailed explaination of the reasons of the results. In summary, to better exchange mutual latest achievements in power industry, it is crucial to keep pace with international new trend, obey international common practice, particularly the rules in English abstracts writing.

Index Terms - power papers, English abstract, voice distribution, active voice, passive voice
\end{abstract}

\section{Introduction}

Abstract is an indispensable part of a paper, which even can decide the paper whether can be included. "In the process of including scientific papers by international retrieval systems, the English abatract is regarded as a key to success. For instance, EI Compendex including papers is decided by English abstract and keywords[1]." This shows how important the abstract is. Meanwhile, as a key industry in China, the development and research of power have to keep track of international new trend, and its English abstract is a crucial hub for communication between domestic and abroad. Therefore, it is of great significance to study the English abstract of power papers.

Divided into active and passive voice, the proper use of voice is one of the key factors in the writing of papers. The famaous linguist Quark pointed out that the frequency of using passive voice in English science and technology is ten times higher than that of active voice[2]. The passive voice is regarded as one of the characteristics of scientific papers.

However, with the constant changes of language, the era of passive voice dominatied in English has changed. International researchers start to advocate widely use active voice in scientific and technological papers.

\section{Related Works}

To further explore the use of voice in various fields in China, domestic researchers have done a lot of statistics and analysis, and their main findings are shown as follows:
$\mathrm{Yu}[3]$ noted that passive voice sentences is conducive on the structure to expanding the amount of information and highlight opinions, conclusions, etc., but he also expressed that using the active voice is more concise than the passive voice, and it is more derect and powerful which can highlight the contants that verb expressed.

Fan[4] studied the use of passive voice in medical papers both at home and abroad, and he discovered that the passive voice sentences account for nearly half of total sentences in domestic, while in the English abstract written by AngloAmerican authors use much more active voice.

Huang[5] conducting a comparative research on English abstracts in Chinese and foreign communication papers found that: "Both Chinese and foreign authors are prone to use active voice in their writng, but authors in English-speaking countries use the active voice frequency (74.8) is much higher than China Author (65.9).

Teng, et al[6] through comparing voice distribution in English abstracts in Chinese and foreign journals find that active voice is dominant in English abstracts in foreign journals, while the English abstract in Chinese journals is passive voice dominated.

$\mathrm{He}$ [7] also made a comparative study on voice distribution in English abstract in Chinese and foreign journals, and found that the English abtstract in domestic scientific journals is dominated by passive sentences, while in the English abstracts in international journals on science and technology, active sentences are far more than passive sentences.

Based on the above findings, foreign scholars advocate to use more active voice in writing articles. Although domestic scholars have conducted much research on voice distribution, but for the power industry few scholars have done the relative studies. The power system as a vital domestic industry, it should keep close with international academic development. Therefore, this paper is devoted to study the master and doctoral dissertation in power industry, focusing on two problems: First, to find out which voive is dominant in English anstract; Second, to conclude the reasons that caused these results. This paper is organized as follows: Section I summarizes the relative research results; Section II describes the research methodology, including sampling corpus, constraints and the research process; Section compares and analizes the results through the lateral and longitudinal respect; then in the fourth section there is a detailed analysis of the causes of the results; Finally, gives a summary of the full text. 


\section{Research Methodology}

\section{A. Corpus Sampling}

In this paper, the 200 samples are randomly selected from masters and doctors papers published between 2011 to 2013, with 100 each seclected from Chinese and foreign power papers. As much as samples can maximize accidental events; by comparing English abstracts at home and abroad can make the result more convincing.

\section{B. Constraint Conditions}

1) To simplify the research process, highlighting research priorities, we have the following constraints in the sample sampling procedure:

2) In order to ensure the reliability of the data, only collected papers published between 2011 and 2013;

3) Only count the first author's nationality, to ensure the accuracy of the data, only count the Anglo-American foreign nationality;

4) Only count the voice of predicate in main clause, ignore sub-clause;

5) The compund sentence by "and, but, while" can be seen as a separate sentence;

6) If a single sentence's verb is "be / have + verb", copula and non-transitive verb, then it counts as non-voice sentence;

\section{The Process of Research}

After collecting thesamples, two corpus of domestic and abroad are constructed; gradually counts the number of active sentences, passive sentences and non-voice sentences, records and adds together, finally gets two sets of data, each data include: the total number of sentences, active sentences, passive sentence, non-voice sentence; then each respectively divide the total number of sentences, so we can obtain the percentage of active voice, passive voice and non-voice; finally compares and analyzes these data.

\section{Results and Analysis}

Based on the comparative study on voice distribution in 200 English abstracts, as shown in Tab.1, the total sentences of 100 English abstracts in domestic papers is 1465, while the total sentences in foreign papers is 1602 . The percentage of active sentences in domestic papers is $28.5 \%$, the percentage of passive sentences is $38.7 \%$, and the percentage of non-voice sentences is $32.8 \%$, in which passive voice accounts for the most percentage. In contrast, the percentage of active sentences in foreign papers is $50.9 \%$, accounting for a half, the percentage of passive sentences is $22.3 \%$, and the percentage of non-voice sentence is $26.8 \%$.

TABLE I Voice Distribution in English Abstracts of Chinese and English Power Papers

\begin{tabular}{|c|c|c|c|c|c|c|c|c|}
\hline \multirow{2}{*}{ Areas } & \multirow{2}{*}{ Number of samples } & \multirow{2}{*}{ Total sentences } & \multicolumn{2}{|c|}{ Active voice } & \multicolumn{2}{|c|}{ Passive voice } & \multicolumn{2}{c|}{ Non-voice } \\
\cline { 5 - 9 } & & & Sentence & Percentage & Sentence & Percentage & Sentence & Percentage \\
\hline China & 100 & 1465 & 418 & $28.5 \%$ & 567 & $38.7 \%$ & 480 & $32.8 \%$ \\
\hline International & 100 & 1602 & 816 & $50.9 \%$ & 357 & $22.3 \%$ & 429 & $26.8 \%$ \\
\hline
\end{tabular}

From the lateral view, Fig.1 is the voice distribution in English abstracts in power papers, as seen from the fiture, the English abstracts in domestic power papers is still dominated by passive voice, followed by non-voice and active voice, the percentages are $38.7 \%, 32.8 \%, 28.5 \%$; meanwhile, percentage of non-voice sentence is almost close to the passive voice.

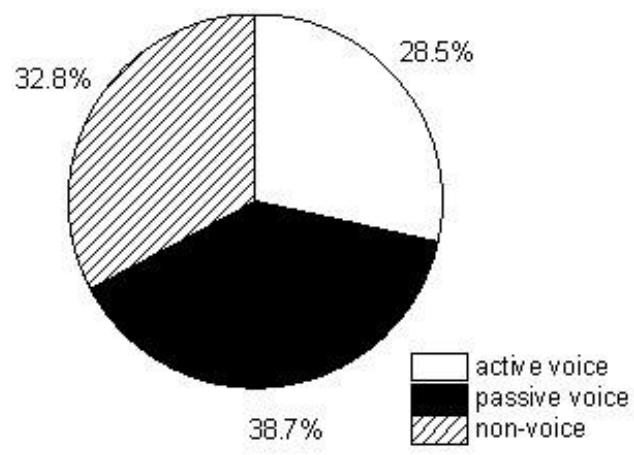

Fig. 1 Voice distribution in English abstracts of Chinese power papers
Fig.2 is the voice distribution in English abstracts in foreign power papers, as shown in the figure, in the English abstracts in foreign power papers, the active voice dominates, followed by non-voice and passive voice, the percentages are $50.9 \%, 26.8 \%, 22.3 \%$; wherein the percentage of the active voice accounts for more than half.

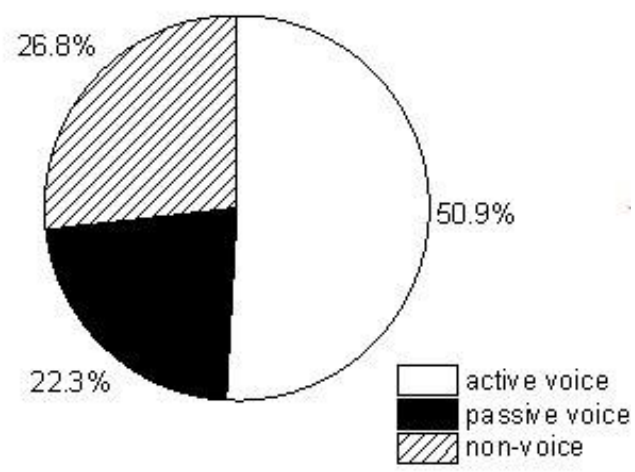

Fig. 2 Voice distribution in English abstracts of English power papers 
This result is consistent with Fan Xiaohui, Teng Zhenru, Tan Wanqing and He Ruiqing. Thus, the use of voice in English abstracts in Chinese and foreign power papers is of significant difference, now in foreign countries the active voice is dominant, while in domestic passive voice is frequently employed. But their common point is that both of them using more non-voice than passive voice.

From the vertical perspective, Fig.3 shows the voice distribution in English abstracts of Chinese and English power papers. As seen from the figure, foreign authors use more active voice than Chinese authors, the percentage of using the active voice in foreign papers is twice than domestic papers. On the contrary, passive voice is more often used in domestic papers, and its percentage is nearly twice than that of foreign papers. But the percentage of using non-voice is nearly same both at home and abroad..

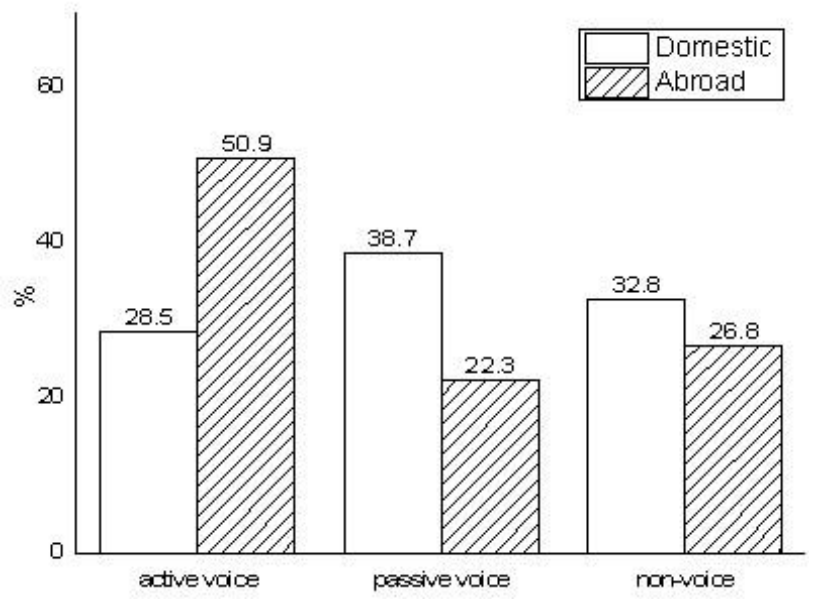

Fig. 3 Voice distribution in English abstracts of Chinese and English power papers

\section{The Reason Analysis}

\section{A. The Reason Why Passive Voice Dominated in English Abstracts in ChinesePower Papers}

1) The Feature of Power Papers Affects the Selection of Voice As most of domestic English abstracts are translated from Chinese abstracts, so choose what kind of voice in the translation depends primarily on the characteristics of Chinese abstract. The main features of scientific papers are structured, logical, accurate and concise. Therefore, as Li Juanli wrote in her paper: "English Abstract in Power Technology papers also belongs to Technology English (EST) category, so in the abstract generally focused on objective, non- emotional, often using the third person passive voice to highlight its technology and objectivity[8]." Yu Jianping held the same view with Li Juanli, he believes that when translating Chinese abstract into English, the use of passive voice can avoid mention relevant actors, so as to make translation more objective . Furthermore, passive sentences in the structure is conducive to expand the amount of information and highlight the conclusions[3]. As mentioned above, due to power itself has a strong scientific papers and objectivity, passive voice is more objective and logical than active voice, and thus the translator prefers to use passive voice when translated Chinese abstract.

\section{2) Excessive Follow the Writing Style of Chinese Scientific Journal}

Scientific journal has been the most popular resources for numorious masters and doctors to use for reference. According to Teng Zhenru, He Ruiqing, Zhang Chunfang and other domestic scholars' findings, we can know that currently the English abstract in domestic journals is still dominated by passive voice. So in the long-term process of reference and study, many masters and doctors naturally formed a habit of overusing passive voice in their English writing. Besides, the national standard GB6447-86 "Digest writing rules[9]", explicitly stipulate to use the third person rather than the first person, if Chinese sentence without subject shoud be translated into English, passive voice is often the prefered. So, it makes students more likely to use passive voice in their writings. In addition, since many students are easy and convenient to get domestic journals, but sedom read international journals, so most of them know little about the international journal standard for voice use. But currently, the American Journal of retrieval "EI" requires to frequently use short sentences, usually with the active voice[10]. Due to lack of the knowledge of the new trends in international journals, and blindly imitate the traditional writing style of domestic journals, it leads to significant differences in the voice distribution at home and abroad.

3) Traditional scientific writing style leads to thinking set

In 1980 John Swales writings have been translated into Chinese, a passage in the book was cited by numerous Chinese scholars: "In any one of physics, chemistry or engineering textbook, it appears that at least one third of the verb using the passive voice ... so extensive use of the passive voice is a remarkable syntactic feature in science English." These words laid a deep imprint in the hearts of many people[11]. Therefore, some translators are affected by this traditional view, only use passive voice and regard it as a doctrine, resulting in appearing a lot of front-weight sentences, not only cannot highlight the information but also often makes syntax errors in translation[12].

\section{B. The Reason why active voice Dominated in English Abstracts in foreign power papers}

On the aspect of voice and person use in English abstract in scientific papers, domestic authors are prone to use passive sentence and the third person, while the international standard ISO 21421976 (E) has advocated the use of the active voice as much as possible, so as to make the article more clear and concise. However, if there is a need to emphasize the action taker, the passive voice might be choosed. Ma Jinlong noted in his paper that the reason why active voice dominated in foreign English abstract is that active sentence is more convenient to write, but in addition it may be related to their individual values that usually emphasized by the AngloAmerican culture[13]. 
Furthermore, in the explaination of the reason why active voice is dominant in English abstract in foreign countries, Fan Xiaohui pointed out that because English is often expressed by the verb action, if the sentence is expressed by the action verb, the sentence becomes direct and understandable, but if the action in the sentence is expressed by nouns, the sentence becomes obscure. Use active voice can tranform the abstract nouns into verbs, so that the sentence structure is more concise, the action is more prominent[4].

\section{Conclusion}

In recent years, many foreign scholars and researchers advocate the use of the active voice, make the article more concise and clear, and keep in line with the mainstream of international academic development. Although there are many Chinese scholars have conducted comparative studies on voive distribution in English abstract in domestic and abroad, but those studies didn't involve in the power papers. However, renowned as an important industry, academic research on powet cannot be line with international standards, and just maintain its traditional writing style, so few acdemic papers can be inclued by international journals, and indirectly influenced the time to display the latest achievement to the world. Therefore, we should keep pace with international standards for better making academic communications.

Of course, choosing which voice should be decided by conditions, rather than seeing it as a doctrine. After all, language is constant chaning, the ultimate purpose of writing papers lies in publishing on journals. Therefore, before writing the English abstract, one should make a rough knowledge of strict standards of voice use in journals, and then choose appropriate voice.

\section{References}

[1] C.R Xiong, "On the International Indexing Standards of Sci-tech Papers in English". Journal of Nanjing University of Aeronautics and Astronautics (Social Sciences), 2009, no.4, pp.83-86.

[2] R QUIRK, D CRYSTAL, P EDUCATION. "A comprehensive grammar of the English language". Cambridge Univ Press, 1985.

[3] J.P Yu. "Problems in Translating Scientific Papers From Chinese into English". Chinse Translators Journal, 2001, no 1, pp.32-34.

[4] X.H Fan. "Overpassivization in English Abstracts in Chinese Medical Journals". Chinese Science \& Technology Translators Journal, 2005, vol 18, no.4, pp.11-14.

[5] J.J Huang. "Voice Distribution in English Abstracts in Chinese and Foreign Communication Papers". Overseas English,2010,vol 150,no.5

[6] Z.R Teng, W.C Tan. "The Problems of Tense and Voice in English Abstracts". Chinese Science \& Technology Translators Journal, 2004, vol.17, no.1, pp.5-7.

[7] R.Q He. "A Comparison between Chinese and Foreign Scientific and Technical Periodicals--Voice Distribution and Front-Weight Sentence's Use Frequency". Shanghai Journal of Translators for Science and Technology, 2004, no.1, pp.16-19.

[8] J.L Li. "Brief Introduction of Electric Power Thesis' Title and Abstract Translation". Qinghai Electric Power, 2003, no.1, pp.61-63.

[9] 86G. Rules for Abstracts and Abstracting.1986.

[10] X.R Sun. "A Practical Guide for Scientific English Writing". Tsinghua University Press, 1997.

[11] C.F Zhang, Z.X Liu. "Voice Distribution in English Abstracts of Chinese and English Scientific Papers". Journal of Jiangsu Polytechnic Yniversity, 2009, vol.10, no.3, pp.105-108.

[12] H.J Li, D.L Wu. "Changing of Sci-tech English and Its Translation". Shang Journal of Translators,2006, no.3, pp.28-31.

[13] J.L Ma. "On the Standardization of Abstract Writing and Translation". Technology Supervision in Petroleum Industry, 2001, no.10, pp.26-28. 